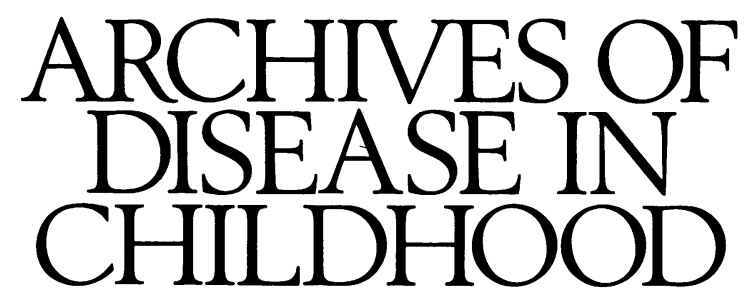

The fournal of the British Paediatric Association

\title{
Editorial
}

\section{Duplicate publication and related problems}

The editors of several international general paediatric journals have been concerned about two problems that weaken the quality of papers submitted for publication. One is the duplication of data in papers submitted to several journals, a practice known as self plagiarism. ${ }^{1}$ The other is the practice of dividing a study up into numerous short reports; this results in what has been called the 'least publishable unit'. ${ }^{2}$ Commonly, these submissions are presented simultaneously to different journals. We suspect that these practices are based on the desire to expand one's list of publications so as to enhance one's reputation and the chances of achieving promotion and academic tenure. In an effort to discourage these practices, the editors of the general American paediatric journals began some years ago to inform one another when they encountered examples of duplicate publication. Editors of European paediatric journals expressed interest in joining this informal network. We offer this collective statement primarily in the hope of discouraging this unnecessary proliferation of articles. We believe that more comprehensive reports will make more substantive additions to the paediatric literature.

We remind authors that when papers are submitted for consideration, they must be accompanied by assurances that the work is original and has not, or will not, be submitted elsewhere. In many instances over the last few years, we have received papers from authors who, in our opinion, violated the spirit and the intent of the copyright assignment. We recognise that there can be differences of opinion about the degree of overlap among papers. However, the editor must be informed when similar papers are submitted to more than one journal, and copies of the potentially overlapping manuscripts should be provided. In this way, referees and editors can make a judgment on the issue of duplication. Certainly, the existence of such papers should be indicated by referring to them in the text and listing them among the references. However, by common agreement, presentations at a scientific meeting or submitting an abstract to such a meeting does not constitute duplicate publication, even if the abstracts are to be published. The undersigned editors will continue to inform one another whenever they encounter examples of duplicate publication.

The issue of dividing a study into multiple components containing data that are somewhat different is more difficult because judgment is required to determine when the practice exceeds appropriate bounds. Investigators may feel justified to submit periodic progress reports of their research as information is developed. The test of appropriateness for this practice is the amount of new information provided by a separate publication. It is rarely justifiable to produce multiple papers on different aspects of a single study when the data have been collected over the same period of time; the amount of duplication among the introduction, methods, discussion, and references is usually very great, and we suspect that most authors recognise the problem because the papers are often submitted almost simultaneously to different journals.

A major problem caused by this form of duplicate publication is the 'wasting' of editorial pages. Each journal has a limited number of pages, and duplication of any type means that some papers are not published. Consolidation of small, related papers would enable more authors' work to be published in our journals. Editors should be made aware of such closely related papers, and be provided with a copy of them when that seems appropriate. As in the case of potentially overlapping manuscripts, examples of this practice will be shared with the other editors when they are recognised by one of us.

Another and possibly related concern has been the proliferation of journals, ${ }^{1}$ which has made it more difficult for paediatricians to keep up with the literature. Indeed, there now is a secondary pro- 
liferation of journals designed to deal with the overload by summarising selected publications from the large number printed. During the past 15 years, more than 20 new paediatric publications have been instituted, and they total almost 10 thousand pages each year. We all recognise that the knowledge base is expanding rapidly, but we cannot help but wonder whether there is a need for so many journals, particularly when the number of papers being submitted to many established journals is not increasing significantly. ${ }^{3}$ There is justification for some subspecialty publications, of course, but we believe that the availability of so many pages will inevitably result in a decline in overall quality of accepted manuscripts, based on the need to fill the pages of the many publications, new and old. We do not fear the 'competition' of these journals; rather, we believe that the information overload will reduce the quality of the product and discourage the average physician from even attempting to keep up.

We hope that these comments will be helpful to contributors to the general paediatric journals and will be seen as they are intended-as a constructive effort to maintain the quality of the paediatric literature. All of us believe that the reading of journals should be the fundamental method of continuing medical education for physicians. If that is true, all paediatricians will be benefited by a reduction in the quantity and improvement of the quality of what is published.

\footnotetext{
1 Relman AS. Publish or perish-or both. $N$ Engl $\mathcal{f}$ Med 1977;297:724-5.

2 Broad WJ. The publishing game: getting more for less. Science 1981;211:

3 Stossel TP. Declining American representation in leading clinical-research journals. N Engl f Med 1990;322:739-42.
}

D M BIER, MD Editor, Pediatric Research

V A FULGINITI, MD Editor, American Fournal of Diseases of Children

J M GARFUNKEL, MD Editor, fournal of Pediatrics

J F LUCEY, MD

Editor, Pediatrics

J SPRANGER, MD

Editor, European fournal of Pediatrics

H B VALMAN, MD

$M$ L CHISWICK, MD

Editors, Archives of Disease in Childhood

R ZETTERSTROM, MD

Editor, Acta Paediatrica Scandinavica 